\title{
Devenires de la corporalidad femenina en Fruta podrida (2007) de Lina Meruane: Toxicidad, memoria y exterminio*
}

\author{
The Becoming of Female Bodies in Lina Meruane's Fruta \\ podrida (2007): Memory, Toxicity and Annihilation
}

\author{
CYNTHIA FRANCICA \\ Departamento de Literatura, Facultad de Artes Liberales, \\ Universidad Adolfo Ibáńez. Santiago, Chile. \\ cynthia.francica@uai.cl
}

El presente artículo propone una lectura de la novela Fruta podrida (2007) de la escritora chilena Lina Meruane en términos de su consistente exploración de las potencialidades del cuerpo femenino. Dichas corporalidades se articulan a través de imaginarios y prácticas de contaminación y toxicidad asentados tanto en la interpenetración de lo humano, lo animal y lo vegetal como en estrategias y materialidades escriturales y de lectura. Los imaginarios tóxicos habilitan múltiples modos de 'devenir' que, a su vez, inauguran nuevos abordajes a la construcción contemporánea del cuerpo femenino en el contexto del campo chileno en estrecha conexión con complejos sistemas globales de producción económica e identitaria. Así, en esta novela la toxicidad visibiliza prácticas y corporalidades implícitamente marcadas en términos de género, raza, clase social y origen geopolítico, así como también sujetos, memorias e historias locales del campo chileno.

Palabras claves: cuerpo femenino, toxicidad, campo, literatura chilena, Lina Meruane.

This article proposes a reading of the novel Fruta podrida (2007) by Chilean writer Lina Meruane in terms of its consistent exploration of the potentialities of the female body. Such corporalities are articulated through imaginaries and practices of contamination and toxicity based both on the interpenetration of the human and the non-human and on writing and reading strategies and materialities. Toxic imaginaries enable multiple modes of 'becoming' in the novel which, in turn, inaugurate new understandings of the contemporary articulation of the female body in the context of the Chilean countryside in close relation with complex global systems of economic and subjective production. Thus, in this novel toxicity operates to visibilize bodies and practices implicitly marked

* El presente artículo forma parte del proyecto Fondecyt $\mathrm{N}^{\circ} 11180229$ "Más allá de lo humano: Cuerpo femenino y afecto en la literatura y las artes visuales contemporáneas de Chile y Argentina”, a cargo de la Dra. Cynthia Francica. Agradezco también el apoyo del Centro de Estudios Americanos (CEA) y la Facultad de Artes Liberales de la Universidad Adolfo Ibáñez. 
in terms of gender, race, social class and geopolitical origin, as well as the subjects, memories and local histories of the Chilean countryside.

Keywords: female body, toxicity, countryside, Chilean literature, Lina Meruane.

\section{DeVenires de la corporalidad femenina en FrUta podrida (2007) De Lina Meruane: TOXICIDAD, MEMORIA Y EXTERMINIO}

La obra Fruta podrida (2007) de la escritora Lina Meruane, premiada como Mejor Novela Inédita de 2006 por el Consejo Nacional de la Cultura y las Artes en Chile, nos presenta una instantánea del campo chileno. Meruane, nacida en 1970, es una de las escritoras más destacadas de su generación y ha escrito tanto obras de ficción, entre las que se encuentran Las infantas (1998), Cercada (2000), Póstuma (2000) y Sangre en el ojo (2012), como trabajos de no ficción, incluyendo los ensayos Viajes virales: La crisis del contagio global en la escritura del SIDA (2012) y Contra los hijos (2018) y la crónica Volverse palestina (2013). A lo largo de su producción es posible rastrear la insistente emergencia de ciertos tópicos como la monstruosidad, la corporalidad, subjetividad y sexualidad femenina, y preocupaciones en torno a la enfermedad y la infección, que se exploran a partir de distintos registros y constituyen un marco amplio de indagación que permea, a su vez, Fruta podrida. ${ }^{1}$ En esta novela el campo chileno emerge como un espacio en crisis asediado por la amenaza incierta pero constante de las plagas que merman la producción agrícola, la precariedad y la inestabilidad laboral de las protagonistas y las temporeras que trabajan la cosecha, las demandas productivas en pos de la exportación de la fruta, y la toxicidad que se cuela, bajo el signo de los pesticidas, el veneno, la medicina y la enfermedad, en el mundo de dos hermanas, Zoila y María del Campo. Un mundo en descomposición cuyos ritmos se encuentran sujetos a fuerzas que, innombradas, subyacen y animan los eventos y situaciones de la novela. Mientras que María, la hermana mayor encargada de realizar el trabajo pesado de supervisión de la producción de la fruta para una empresa internacional, se embaraza cada nueve meses para vender sus bebés en el mercado negro de experimentación médica y trasplante de órganos, su media hermana menor Zoila, hija de un exportador extranjero y una mujer local, se enferma de diabetes y se niega obstinadamente a recibir el tratamiento prescripto por los médicos que, informados por los avances y las visitas de colegas del Norte adonde se exportan las frutas que ellas producen, intentan extender su vida por todos los medios.

\footnotetext{
${ }^{1}$ Si bien este artículo se centra en Fruta podrida, es importante consignar que las preocupaciones y temáticas que emergen en este texto forman parte de un universo de significación más amplio que la autora teje no sólo a través de su producción literaria sino también mediante sus indagaciones teórico-críticas. Así, la exploración de la enfermedad se presenta tanto en Viajes virales a través del registro académico como en Sangre en el ojo desde la textualidad del formato novela; mientras que la pregunta en torno al género, lo femenino y la sexualidad se enmarca en obras como Las infantas y en su ensayo Contra los hijos; y lo monstruoso reaparece tanto en Sangre en el ojo como en Las infantas.
} 
La novela plantea una pregunta central: ¿cómo interpretar cuerpos femeninos que se resisten a ser leídos, definiéndose como perpetuamente en exceso y en continuo devenir, perpetuamente contaminados y, por tanto, inabarcables? Se trata de corporalidades que, como veremos, se constituyen a partir de y se orientan constantemente hacia lo animal y lo vegetal, cuerpos ilegibles bajo el paradigma sintomatológico -un paradigma hermenéutico paranoico- de la medicina moderna. Cuerpos que sufren fiebres "que el termómetro no registra" (Meruane 2007: 38), cuerpos violentados y amputados cuyos miembros fantasma, en el caso de una paciente anciana del hospital, se pueblan de hormigas y se resisten a cicatrizar, evidenciando una permeabilidad y apertura radical al medio y a otros cuerpos y organismos, incluyendo los de la putrefacción.

Ampliando los términos del debate en la línea que sugiere la teórica feminista Elizabeth Grosz (2011), me interesa plantear la pregunta acerca de cómo el estudio de marcos narrativos en que el sujeto femenino se concibe no sólo de acuerdo a entornos culturales humanos sino también a geografías materiales, naturales e inanimadas puede ayudarnos a repensar tanto la representación del cuerpo femenino en la literatura latinoamericana como las herramientas hermenéuticas de la crítica literaria. Esto resulta de particular importancia en el caso del estudio del género y la sexualidad femenina entendidos, en términos Foucaultianos, como construcciones biopolíticas sujetas a constante regulación y disciplinamiento. ${ }^{2}$ Como afirma el crítico norteamericano Mel Chen, "los modos en que los objetos inanimados y los animales no humanos participan en los regímenes de la vida...y la muerte coercitiva... son integrales al esfuerzo de comprender cómo funciona el bio-poder y cuáles son sus materiales" (Chen 2012: 6) ${ }^{3}$. Asimismo, en el contexto del actual 'giro afectivo' ${ }^{4}$ en la teoría crítica, la categoría de 'afecto', entendida como "la capacidad de un cuerpo de afectar y ser afectado" (Chen 2012: 2), ha cobrado relevancia creciente en los debates acerca de la corporalidad. Baruch Spinoza define la noción de 'afecto' a grandes rasgos como la capacidad de actividad y respuesta de un cuerpo. Por su parte, la teórica Jane Bennett propone la categoría de 'afecto impersonal', expandiendo el alcance del término para incluir a cuerpos y objetos no

\footnotetext{
${ }^{2}$ Ver Foucault (1998) para un abordaje detallado a la historia del disciplinamiento y la normalización de la corporalidad y la sexualidad del sujeto moderno.

${ }^{3}$ Mi traducción. Todas las traducciones del inglés al español en este artículo han sido realizadas por la autora.

${ }^{4}$ El denominado 'giro afectivo', que se despliega a partir de la década de 1990, constituye el más reciente resurgimiento de interés en los fenómenos afectivos, habilitando variadas perspectivas teóricas y metodológicas para el estudio de estos últimos. Más que a partir de una corriente teórica uniforme, el 'giro afectivo' comprende un variado espectro de lenguajes y herramientas de interpretación provenientes de distintos paradigmas y áreas de estudio. Según Melissa Gregg y Gregory Seigworth, las condiciones de posibilidad de esta renovada atención crítica a la dimensión afectiva estuvieron dadas por una serie de vectores que incluyen las teorías fenomenológicas y post-fenomenológicas de la corporalidad; tradiciones no cartesianas en filosofía; la cibernética y las teorías del hombre-humano-inorgánico; el feminismo, la teoría queer, los estudios subalternos y de la discapacidad; aspectos de la teoría psicológica y psicoanalítica; teorías críticas e historias de las emociones y ciertas ramas de la ciencia y la neurología (Gregg \& Seigworth 2010: 6-8).
} 
humanos. Bennett concibe, así, el afecto como "un poder que, más que transpersonal o intersubjetivo, es impersonal [e] intrínseco a formas imposibles de imaginar (incluso idealmente) como personas" (Bennett 2010). En términos de Deleuze y Guattari,

no sabemos nada acerca de un cuerpo hasta que comprendemos lo que puede hacer, en otras palabras, cuáles son sus afectos, cómo éstos pueden (o no) entrar en contacto con otros afectos, con los afectos de otro cuerpo... destruir ese cuerpo o ser destruidos por él...intercambiar acciones y pasiones con él o unírsele para componer un cuerpo más poderoso aún (Deleuze \& Guattari 1987: 257).

En este sentido, la búsqueda narrativa de Meruane puede leerse en términos de una exploración de las potencialidades del cuerpo femenino; un cuerpo que, en su escritura, se define justamente a partir de su capacidad de afectar y ser afectado, y de su compleja interrelación con otros cuerpos, seres y objetos. En particular, me interesa proponer que los cuerpos femeninos de la novela se articulan a través de imaginarios y prácticas de contaminación y toxicidad. Dichos imaginarios se asientan, por un lado, en la interpenetración de lo humano, lo animal y lo vegetal y, por otro, en estrategias y materialidades escriturales. La putrefacción se vuelve en el caso de estos cuerpos un modo de 'devenir' al tiempo que visibiliza flujos de interpenetración y comunicación no sólo entre cuerpos humanos sino también inter-especie. Asimismo, los imaginarios tóxicos emergen en la obra de Meruane como una vía posible para pensar la construcción del cuerpo femenino en estrecha conexión con complejos sistemas globales de producción económica e identitaria en el contexto contemporáneo del campo chileno. Como elaboraré a continuación, la novela estrecha los vínculos entre cuerpo y territorio en tanto los cuerpos materializan con insistencia las tensiones entre historias, intercambios y economías locales y globales. Frente al borramiento de la historia local del campo chileno desatado por el influjo de lo global y la consecuente redefinición del territorio, las corporalidades femeninas disidentes cargan con y toman forma a partir de memorias comunales en la novela. A la vez, en Fruta podrida es justamente a partir del devenir (in)material de esas corporalidades que se dirimen los modos en que los imaginarios locales viajan y se despliegan en otras latitudes. Trazando economías afectivas asentadas en intercambios globales e inter-especie, los imaginarios de contagio y toxicidad de la novela producen cuerpos otros que habitan posiciones siempre liminales, oscilando entre lo local y lo global, lo humano y lo animal, el pasado y el presente, al tiempo que visibilizan nociones y prácticas políticas implícitamente marcadas en términos de género, raza, clase social y origen geopolítico.

\section{El CUERPO FEMENINO EN DEVENIR Y LO VIVIENTE}

Desde el comienzo mismo del texto y a medida que avanza la novela, se va conformando una red o tejido que permite hilar conexiones subyacentes entre animales, 
plantas, frutas y los cuerpos de los personajes. Anticipando el despliegue de esa compleja red conceptual y material, el texto comienza de la siguiente manera:

Era el sol reventado en el horizonte. Eran los buitres oteando la carnosa pulpa del campo, las garras empuñadas en la alambrada de púa o adheridas a los ardientes techos de zinc, fijos los ojos sobre la calurosa casa de adobe... Ya la cosecha estaba siendo despachada. Ya los zorzales espantados, y los guarenes. Ya los gusanos exterminados, las hormigas aturdidas. La mosca de la fruta era todavía una amenaza incierta y aún no empezaban a rechinar los grillos de la noche; no se habían encendido las hélices de las luciérnagas (Meruane 2007: 13-14).

A su manera, los animales, insectos y plagas asedian la estructura textual para revelarse, como en el espacio del campo, obcecada e implacablemente presentes. El esfuerzo de eliminarlos por parte de María con el objeto de preservar la cosecha resulta en última instancia no sólo infructuoso sino radicalmente revertido por la misma protagonista, quien decide, en un acto terrorista hacia el final del texto, envenenar la fruta perfecta y pura que tanto trabajó por producir. A su vez, la novela se sirve constantemente de imágenes vegetales para describir el cuerpo femenino: el páncreas es una "berenjena oscura y rugosa" (Meruane 2007: 27); a medida que avanza su enfermedad y aumentan las "cifras de azúcar" en su sangre, el cuerpo de Zoila se torna "una fruta ya madura" (Meruane 2007: 81); los órganos embotellados en la consulta médica del hospital que las hermanas visitan en búsqueda de un diagnóstico y tratamiento para Zoila son "frutos en conserva. Fruta perfecta como las que ella (la Mayor) estaba produciendo cada temporada en el campo" (Meruane 2007: 23).

Más allá de estas y las múltiples imágenes animales y vegetales que pueblan el texto, me interesa señalar que moscas y hormigas adquieren un protagonismo insistente - moscas y hormigas vuelven una y otra vez a definir espacios, cuerpos y situaciones, a infectar el texto. ${ }^{5}$ Moscas y hormigas en tanto plagas agrícolas que, en la novela, se revelan en continuidad con o como extensión viva de los cuerpos de Zoila y María. Desde el comienzo mismo del texto, Zoila es descripta como "un bicho recién fumigado... una mosca enredada en la alfombra de la arańa, el puro armazón de un insecto recién vaciado" (Meruane 2007: 15). En esta línea, en un punto de la novela Zoila, con su hambre voraz, se alimenta de moscas, materializando la literal continuidad de su cuerpo con el de estos insectos:

Aparezco junto a una ventana alfombrada de moscas; estoy sentada frente a ellas, hipnotizándolas con un dedo. Quietas, les susurro, apuntándolas, lentamente acercándome, quietas mis dulces y negras moscas. Se quedan tiesas sobre el vidrio, estupefactas; y entonces zas, aplasto una con el índice y me la meto en la boca: esa mosca levemente amarga patalea agónica sobre mi lengua. Y zas, aplasto otra, más

\footnotetext{
${ }^{5}$ Reflejando visualmente dicho protagonismo, en la tapa de la novela Fruta podrida en su edición del año 2015 de la editorial argentina Eterna Cadencia figura la imagen de una mosca.
} 
gorda, más amarga cuando la exprimo entre los labios. Ninguna se me escapa, y en eso estoy, engullendo la quinta o sexta lerda mosca de la tarde cuando zas, aparece mi hermana por detrás, y con su mano entera metida en mi boca, tocando la campana de mi garganta, me hace expulsarlas todas. A todas mis negras y amargas moscas (Meruane 2007: 35).

La abyección latente en las imágenes de este pasaje -abyección evocada no sólo a través de la corporalidad de estos insectos sino también del consumo tabú, lo excrementicio y el vómito- (con)funde el cuerpo de Zoila con la pegajosa materialidad de las moscas. El cuerpo de la protagonista se revela, así, como un vaso comunicante, una materia moldeable capaz de constituir ensamblajes inesperados e inestables con otros seres y cuerpos. A su vez, el constante efecto especular entre ambas hermanas a lo largo de la novela se cristaliza aquí en un gesto corporal abyecto: como Zoila en este pasaje, María engulle sus comidas para luego, rigurosa, vomitarlas (Meruane 2007: 35).

Asimismo, al igual que moscas y hormigas, María y Zoila son atraídas y repelidas por los olores, los sabores y la química del azúcar, los pesticidas y la enfermedad. Con su híper desarrollado sentido del olfato, la Mayor es capaz de detectar instintivamente los más mínimos indicios de putrefacción y toxicidad. Cuando, al comienzo del texto, Zoila se desmaya a raíz de su aún no diagnosticada diabetes, María no sólo detecta el olor a “empalagosa podredumbre" que emite su boca abierta (Meruane 2007: 16) sino que también lo rastrea en el espacio de la casa con el fin de descubrir su punto de origen en la taza de baño, en la orina. En el momento de esta epifanía, al igual que María y presuntamente trazando un recorrido espacial similar tras la pista química del particular aroma, las hormigas ya habían llegado a destino: "cuatro hormigas flotaban en la orilla de loza blanca y otras enfilaban aceleradamente por el borde dispuestas a morir. Hormigas incansables e inconscientes salidas quizás de dónde. Hormigas laboriosas con un solo objetivo" (Meruane 2007: 17-8). Entonces la Mayor, perpetuamente embarazada,

sumergió la palma de la mano y la sacó como un cucharón...Y tragando la orina que le cupo dentro pensó en hormigas ahogadas, y en alcohol, y en acetona, y en el precio del azúcar...entre las arcadas, al secarse la bilis amarga de los labios, apareció una idea precisa: la Menor estaba fermentando (Meruane 2007: 18, mi énfasis).

La Mayor ostenta en este pasaje capacidades olfativas y gustativas excepcionales que la posicionan en directa continuidad sensorial y espacial con el universo animal.

A su vez, la imagen de la fermentación de Zoila remite a los modos en que, en Fruta podrida, "el estado humano se continúa en el estado vegetal", subrayando la amplitud de la potencialidad de los cuerpos (Keizman 2017 112). Desde una clave fenomenológica, Sara Ahmed propone que los cuerpos, lejos de constituir entidades fijas y auto-contenidas, "toman forma a medida que se extienden y orientan hacia los objetos cercanos y disponibles en el horizonte corporal" (Ahmed 2006). El cuerpo de Zoila parece tomar forma a medida que 
se extiende y orienta hacia el mundo material que la rodea, manifestando una enfermedad marcada por el desbalance químico del azúcar - el azúcar como sustancia esencial de la fruta que determina circuitos de producción económica global. Después de todo, si María reconoce el olor que despide la orina de Zoila es precisamente porque ésta evoca el aroma de la fruta que constituye la base misma de la economía agraria - de hecho, en el pasaje anterior la idea del precio del azúcar se le presenta inmediatamente antes de su epifanía. El azúcar se vuelve, en el caso de las hermanas, veneno y deseo, muerte y porvenir, al tiempo que opera para visibilizar la agencia y autonomía del cuerpo deseante de Zoila - un cuerpo enfermo que transita, cual hormiga, una búsqueda obcecada de lo dulce pese a la prohibición y, en esa búsqueda, cede y se re-orienta hacia sí mismo al tiempo que desestructura cualquier discurso que pueda construirse en torno a él. ${ }^{6}$

En sus respectivos análisis de la novela, tanto Betina Keizman (2017) como Isabel Quintana (2017) señalan la capacidad de resistencia de estos cuerpos en mutación frente a marcos biopolíticos normativos. Las instituciones médicas, políticas y económicas ejercen presión sobre los cuerpos del texto, imponiendo cuotas abusivas de (re)producción y un concomitante imperativo de prolongación de la vida (de las frutas y los cuerpos) a cualquier costo que mujeres como Zoila resisten desde un obcecado apego a la enfermedad, la contaminación y la muerte. En este sentido, a través de su referencia al contexto chileno y a una concomitante ideología neoliberal incapaz de concebir la libertad individual si no es en estrecha relación con el mercado, Fruta podrida "muestra el resultado de la dictadura: la economía de la fruta y los cuerpos. Ambos actúan como una metonimia del carácter exitoso que tanto se enorgullece de las cifras nacionales: fruta cuidadosamente sanitizada para la exportación, el cuerpo de una mujer medicamentado para procrear para la ciencia" (Barrientos 2015: 92). Así, tanto la fruta como el cuerpo femenino se ven sujetos a procesos intensivos de control y disciplinamiento, de modo tal que cuando dichos procesos fracasan quedan tan sólo restos bajo la forma de frutas imperfectas o envenenadas y, por tanto, descartadas, o de cuerpos enfermos como el de Zoila que habita, hacia fines de la novela, un espacio de marginalidad social, cultural y biológica. En este sentido, me interesa sugerir que, explotando conexiones latentes con otros cuerpos y seres, los sujetos femeninos de la novela participan de una serie de 'devenires' que habilitan formas otras de pensar la problemática de género. Me propongo indagar aquí los modos en que los cuerpos marcados en términos de género y sexualidad se resignifican y, literalmente, toman forma en la novela en estrecha relación no sólo con sistemas globales de producción económica e identitaria sino también con procesos políticos de historia y memoria colectiva local. La potencia disidente de estos cuerpos femeninos se asienta en su capacidad de modular registros de toxicidad y contaminación intra e inter-especie que impactan las estrategias escriturales, de lectura y significación puestas en marcha en la novela. Desde esa plataforma y a partir de dichas estrategias, el texto visibiliza

\footnotetext{
${ }^{6}$ Por un lado, esa desestructuración discursiva tiene lugar, como discutiré más adelante, en el proceso mismo de escritura y lectura de Zoila. Por otra parte, en el comienzo de la novela la Menor sufre un desmayo ante la falta de azúcar que se expresa textual y visualmente en la página, de modo tal que la escritura retoma el ritmo de su cuerpo enfermo (Meruane 2007: 37-38).
} 
subjetividades marginales en términos de género, raza, sexualidad y clase social; subjetividades que, justamente, tienden a ser representadas a partir de imaginarios de toxicidad.

Según Gilles Deleuze y Félix Guattari, el proceso de 'devenir', mediante el cual al menos dos sistemas se unen para conformar un nuevo sistema emergente o ensamblaje que preserva, a la vez, la heterogeneidad de sus componentes, implica una des-jerarquización, desaprendizaje y desterritorialización de las posicionalidades dominantes (Deleuze \& Guattari 1987). En tanto refiere a la variedad de conexiones potenciales que una cosa es capaz de entablar, el proceso de 'devenir' da paso a la desarticulación de distinciones normativas (y civilizatorias) entre lo humano y lo no humano y su reemplazo por líneas de continuidad y fluidez entre cuerpos disímiles. De esta forma, el 'devenir' Deleuziano "apunta a una desontologización pragmática, práctica (por vía de agenciamientos y de alianzas) de lo 'humano"' (Giorgi 2014: 29). En su descripción de las nuevas políticas y retóricas de lo viviente que definen los lenguajes estéticos de la narrativa argentina contemporánea, Gabriel Giorgi propone que, lejos de una distribución simple entre humano y animal, o una borradura de su diferencia, lo 'viviente' implica "una multiplicidad de zonas de vecindad y de intercambio que no se dejan capturar bajo los modelos previos de 'vida animal' y 'vida humana'...un umbral de relación entre cuerpos y especies ... que se constituye como materia estética" (Giorgi 2014: 35).

En esta línea, más que como entidades auto-contenidas e independientes del medio, las corporalidades femeninas de Fruta podrida emergen y toman forma a partir de su radical apertura hacia cuerpos y objetos no humanos. En el contexto agrícola, el cuerpo de Zoila no sólo se continúa en el estado vegetal sino que, regido por los procesos naturales de la fruta, fermenta de modo tal que las moscas, insistentemente presentes en el transcurrir de la novela y en la escritura autobiográfica de Zoila, se tornan una extensión viva de esa corporalidad femenina proyectada en el espacio del campo y la escritura - de modo tal que las moscas también se vuelven parte de, y constituyen, ese cuerpo enfermo. Si, como discutí anteriormente, el cuerpo femenino de María establece filiaciones inesperadas con la corporalidad, y el recorrido espacial y sensorial, de la hormiga, el insecto-plaga, hacia el final de la novela Zoila, ese "bicho recién fumigado" (Meruane 2007: 15) deviene fruta podrida, deviene plaga, y, contaminada, se vuelve resto. El texto provee varios guińos en esta dirección: siguiendo el protocolo de sanidad agropecuaria, las azafatas rocían la cabina del avión con insecticida durante el viaje de Zoila a Estados Unidos para luego someterla a un control aduanero estricto con objeto de asegurar que no entren al territorio del norte productos agrícolas contaminados (Meruane 2007: 137-140).

Zoila extrema ese 'devenir' cuando poda metafóricamente su propio cuerpo con las tijeras que trae de Chile. Para intentar aliviar la picazón de su pierna hinchada luego del largo viaje, Zoila introduce la hoja de la tijera entre el yeso y su piel y se corta, dando paso a una infección que no trata (Meruane 2007: 140). Su pie infectado, emulando el proceso de poda vegetal, desaparece en un gesto fantástico que culmina la novela. En palabras de la enfermera que, asombrada, revisa al final del texto el cuerpo infeccioso y la pierna enyesada de una Zoila vuelta mendiga: 
[...] voy sumergiendo mis dedos hacia el fondo del yeso abierto. Mis dedos alcanzan un vacío dentro de la bota, oscilan en la cavidad sin haber alcanzado todavía el pie...y entonces fuerzo la mano hasta que alcanzo un charco de líquido espeso, un fluido gomoso. Me detengo, me percato, me pregunto confundida, ¿y el tobillo de la mendiga? ¿Adónde habrá ido a parar el resto de esta mujer? Hay un pedazo extraviado pero mis dedos continúan hurgando sin convencerse de que no hay más que sangre coagulada aquí dentro y allá lejos, en medio de este espantoso silencio que ahora lleno con mi angustia: ¿dónde están el empeine y todos sus frágiles huesos, dónde sus dedos? ¿Dónde el extremo maloliente de este cuerpo? (Meruane 2007: 204).

La poda del cuerpo de Zoila revierte la función productiva de la poda vegetal en términos del disciplinamiento y la aceleración del crecimiento para activar una economía de los restos - su cuerpo femenino abyecto y contaminante es puro resto y, como tal, no encuentra ya ningún uso o propósito (re)productivo ${ }^{7}$.

\section{DeVENIR ESCRITURA, DEVENIR MENDIGa}

La mendicidad, estado por excelencia improductivo desde una perspectiva capitalista, señala el camino del último devenir de la Menor en el Norte a medida que el cuaderno de composición (identificado en el texto como 'cuaderno deScomposición') que utiliza para registrar los avatares de su enfermedad da paso a otras prácticas y estéticas de lectura y escritura asociadas a los periódicos y sus titulares. Es necesario aquí detenerse en la centralidad de la escritura en la novela. El 'cuaderno deScomposición' de Zoila constituye una práctica que articula cuerpo y escritura en la medida en que registra la historia de su enfermedad, con los respectivos síntomas y dosis de alimento y medicación asignados. A la vez, el discurso médico, con su legitimidad social y científica, se desarticula a través del lenguaje poético que irrumpe en el cuaderno en tanto modo alternativo de aprehender los devenires potenciales de la enfermedad. En ese sentido, el 'cuaderno deScomposición' juega un rol fundamental en la subversiva transformación corporal de la protagonista:

$$
\begin{aligned}
& \text { esta espera saturada } \\
& \text { de consonantes y síntomas y } \\
& \text { notas conjeturales y pistas }
\end{aligned}
$$

\footnotetext{
${ }^{7}$ Esa misma atención a los restos se visibiliza en el texto cuando una Zoila apenas aterrizada en Estados Unidos se encuentra con un mendigo en el metro. Con su bolsa de latas que obstaculizan la puerta de entrada al vagón, el mendigo encarna también una economía de los restos - economía precaria e informal de intercambio en los márgenes del sistema capitalista que, en esta escena de la novela, opera disruptivamente para retrasar la partida eficiente del metro y, por tanto, de la multitud de cuerpos trabajadores que constituyen la base del engranaje productivo. En este caso, el carácter subversivo de la estrategia de supervivencia y el modo de vida marginal encarnados por el mendigo se reafirma mediante la intervención del violento aparato policial, que le propicia "golpes mortales" (Meruane 2007: 142).
} 


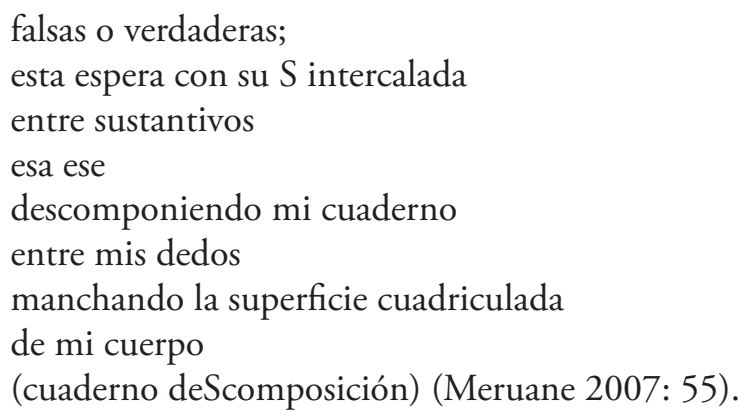

Aquí "cuerpo, escritura y texto se unen en la descomposición de un sistema, ya sea económico o escritural" (Barrientos 2015: 100). En esta línea, me interesa visibilizar los modos en que el devenir de Zoila a lo largo del texto se figura como y se ve posibilitado por prácticas de lectura y escritura, con su capacidad desestabilizadora del lenguaje y el sentido. A su vez, el devenir de la protagonista es, en cierto modo, un devenir lenguaje, devenir escritura. Mientras que en la cita anterior su cuerpo, en contigüidad con su cuaderno, ostenta una "superficie cuadriculada", los diarios consolidan, de un modo diferente pero paralelo, la concepción de la escritura como indisociable de la vida del cuerpo desarrollada a lo largo de la novela: para asegurar su supervivencia en el invierno del Norte, Zoila rellena su abrigo de diarios (Meruane 2007: 200). La inextricabilidad de cuerpo y escritura se manifiesta aquí a nivel concreto: el papel de diario en tanto materialidad escritural no sólo se proyecta como la segunda piel de Zoila sino que constituye un elemento simbólico fundamental de su mendicidad.

Asimismo los diarios, que envolverán luego a Zoila en el banco de plaza fuera del hospital donde se instala, pueden leerse en continuidad con su 'cuaderno deScomposición' en tanto las notas periodísticas ofrecen otro modo de registro de los avatares de la Menor. De hecho, la contigüidad entre ambos modos de escritura emerge de manera literal en la novela: es precisamente "entre todo el papel que lleva entre su abrigo y el cuerpo" que la enfermera, cuando revisa a Zoila en búsqueda de su documento de identidad, encuentra un poema escrito por ésta en el cual da cuenta, una vez más, de su cuerpo infectado (Meruane 2007: 202-203). Los registros periodísticos que Zoila colecciona y lee obsesivamente durante la conversación con la enfermera hacia el final del texto relatan indirectamente la historia de su cuerpo enfermo a través de las noticias de sus ataques anónimos al ala de trasplantes experimentales del Gran Hospital del Norte. En otras palabras, los diarios dan cuenta de los modos en que su corporalidad se despliega, obcecada, en el Norte como agente desequilibrante y amenaza al orden público. A medida que su cuerpo físico comienza literalmente a desaparecer, los periódicos recogen y reproducen su rastro (y su legado disruptivo) en el mundo - Zoila se expande, su cuerpo tóxico se 'viraliza' desde la intimidad de lo privado hacia el dominio de lo público para devenir noticia, amenaza misteriosa, escritura común.

$\mathrm{Y}$ es ese proceso de descomposición el que Zoila resignifica en el trascurso de la novela: su devenir contaminante se extrema hacia el final del texto cuando la Menor se vuelve 
mendiga, abandonando los rituales higiénicos de socialización y disciplinamiento corporal. Cual plaga de la fruta, su cuerpo se torna un resto tóxico gradualmente sepultado bajo la nieve. Es quizás por esto que Zoila se agita cuando le pregunta ansiosa y repetitivamente a la enfermera cuánto tiempo falta para que pase el camión de la basura (Meruane 2007: 185), a lo que esta última responde:

...si tenía usted cita con el camión, o más bien con alguno de los recolectores municipales de basura, es altamente probable...que bajo la nieve ese recolector amigo suyo no la haya visto. Habría tenido que palear y palear para haberla encontrado...la basura demora más en podrirse bajo el hielo... (Meruane 2007: 185-186).

Frente a la crisis presupuestaria de la ciudad, le informa la enfermera, la recolección de la basura se ha visto afectada, lo que resulta en un ambiente insalubre. Y en esa ciudad contaminada, Zoila atentamente espera el paso del camión que habrá de recogerla, cual desecho, en un futuro fantástico. Es a través no sólo de los ataques al ala de experimentación en trasplantes del Gran Hospital sino también, y quizás sobre todo, de ese cuerpo tóxico, estático y en descomposición en los márgenes de las operaciones médicas de gestión biopolítica en pos de la prolongación de la vida que la Menor despliega su cuerpo enfermo como estrategia de resistencia. Dicha estrategia de resistencia se asienta, esta vez, en un código no discursivo: "el lenguaje de las células es el único que verdaderamente comprendes: ese idioma es tu única lengua y es tu mejor arma de ataque" (Meruane 2007: 140). Como señalé anteriormente, el devenir de Zoila, supeditado a la enfermedad, le otorga a su cuerpo tóxico una vitalidad inesperada y fantástica: todo lo que queda de su pie desaparecido es "un charco de líquido espeso, un fluido gomoso" (Meruane 2007: 204). El cuerpo desobediente de Zoila evidencia, efectivamente, su propio lenguaje, un lenguaje de putrefacción, herida, desaparición y ausencia.

\section{DE FÁBRICAS, PIES Y CALCETINES: MEMORIA, TOXICIDAD Y TRABAJO}

El de Zoila no es, sin embargo, el único cuerpo disidente del texto. En un pasaje de la novela, el enfermero que la atiende en Ojo Seco le cuenta a la Menor la terrible historia de una anciana tratada en el hospital del pueblo. La anciana, espejando el devenir de Zoila en el Norte, llega al hospital casi ciega y "arrastrándose como una mendiga”. Los dedos de sus pies "oscuros como castańas... recocidas y blandas por dentro" debieron ser amputados (Meruane 2007: 65). Sin embargo, ante la falta de cicatrización le cortan ambos pies, luego de lo cual la anciana le ruega al Médico que "por favor porfavorcito...le mataran las hormigas que le recorrían día y noche las plantas de los pies" (Meruane 2007: 66). Frente a su insistencia, el médico decide amputarle las piernas. Las heridas de la anciana no cauterizan, y ella exige que la dejen morir. Si bien el médico se niega, un día la mujer amanece muerta, con un 
gesto sonriente y sarcástico en el rostro (Meruane 2007: 68). La amputación de los pies de la anciana se replica, mediante un gesto fantástico, en el cuerpo de Zoila hacia el final del texto, cuando su extremidad desaparece bajo el yeso. ${ }^{8} \mathrm{Si}$ en el caso de la anciana las hormigas constituyen la memoria física y sensorial de un miembro fantasma, lo que queda del pie ausente de Zoila es tan sólo un líquido gomoso y el yeso que una vez lo contuvo. La novela postula, así, una temporalidad compleja en la que el cuerpo y su fantasma, o su memoria, conviven en un presente enrarecido; una temporalidad desacoplada que, ajena a los regímenes de producción capitalista, posibilitaría la emergencia de lo que Keizman denomina "vidas potenciales" (2017). Estos cuerpos femeninos, constituyéndose a partir del resto y el desecho, oscilan entre la vida y la muerte: se encuentran ya habitados por insectos y organismos que marcan la presencia tóxica de la descomposición. Se trata de cuerpos zombies, cuerpos espectrales, muertas vivas que desarreglan la distinción biopolítica entre la vida y la muerte, entre lo humano y lo animal.

Los cuerpos enfermos y disidentes de Fruta podrida constituyen una red, un entramado común, un tejido tóxico en la medida en que resuenan más allá de sí mismos y adquieren un sentido común. Frente al efecto homogeneizador y aplanador de los intercambios globales que estructuran el texto, estos cuerpos reconstituyen y encarnan modos de memoria común centrados en la historia local y el silenciado y precario mundo del trabajo. La instalación del hospital de Ojo Seco, le cuenta el enfermero a Zoila, se vio posibilitada por el dinero de la venta de una fábrica de calcetines cuyo dueño no era otro que el padre del médico que hoy dirige el hospital. En contraste con el modelo económico chileno agroexportador de materias primas que prima en la novela, la exitosa fábrica simboliza no sólo la potencialidad de una economía industrial local sino también, de manera concreta, un medio alternativo de supervivencia y desarrollo para los habitantes del pueblo: “...ahí tejedoras y tejedores producían calcetines a toda máquina. El padre del médico levantó esta zona y la mantuvo de pie incluso después del terremoto: cuando las casas se vinieron abajo todos nos abrigamos con los calcetines de esa fábrica..." (Meruane 2007: 92). Sin embargo, luego de la muerte del dueño de la fábrica, ésta es tomada por los empleados y el sindicato. Será el hijo del dueño, el médico, quien en ese contexto negociará la venta de las instalaciones con los empresarios de la fruta y la llegada al hospital de los equipos médicos del Norte mediante su transporte en los mismos camiones que trasladan la fruta de exportación chilena. Se produce, así, un borramiento de las historias locales desatado por el influjo de lo global y la consecuente redefinición del territorio; borramiento de la potencialidad de una etapa productiva industrial anterior manifestado simbólicamente en la ubicuidad del Alzheimer en el texto, que afecta a la anciana amputada, al Estado norteamericano (según la enfermera, "el Estado es otro anciano con Alzheimer: sobrevive en estado vegetal pero ni siquiera podemos desconectarlo" (Meruane 2007: 167)) y también

\footnotetext{
${ }^{8}$ El paralelismo entre la corporalidad de ambas mujeres es insistente: mientras que el cuerpo de la anciana amputada en el hospital y sus miembros fantasma se vuelven un territorio dominado por las hormigas, en el transcurrir de la novela Zoila escribe acerca de cómo las moscas y sus gusanos colonizarán su cuerpo al igual que lo hacen con la fruta podrida.
} 
a los viejos sindicalistas que, aún empleados perversamente por el médico, cuidan a Zoila durante las hospitalizaciones anuales de María. En este contexto, los pies de Zoila y de la anciana (y los calcetines que los abrigan) materializan los modos en que los cuerpos disidentes cargan con y toman forma a partir de memorias locales y comunales en la novela. El lenguaje celular de la ausencia y la desaparición del pie en el caso de Zoila y el miembro fantasma de la anciana encarnan la historia de los habitantes y el territorio de Ojo Seco en tanto se enlazan con el pasado del pueblo, la antigua producción local, la rebelión de los trabajadores, los fallidos intentos sindicales y la historia del terremoto. El devenir del cuerpo enfermo de Zoila espeja, en este sentido, los avatares de una historia y una comunidad local sometidas a la desaparición mediante un insistente proceso de borramiento.

En su análisis de los cuerpos homosexuales monstruosos y anti-normativos que pueblan la narrativa argentina, Giorgi argumenta que el despliegue de lenguajes, imaginarios y sueńos de exterminio en la representación de esos cuerpos constituye el terreno donde resuenan:

las preguntas por los cuerpos que faltan, en torno al vacío y al espectro del cuerpo eliminado (los lenguajes de la melancolía y el duelo en el límite entre lo posible y lo imposible)... Son sueños porque emergen en los límites o los bordes de la realidad, como proyecto, o al revés, como memoria de lo ausente, del cuerpo que ya no existe (y que parece 'no haber existido nunca'): sueńos en los que la realidad se reinventa, se transforma, se altera, y da testimonio de esa transformación, que se lleva a cabo al precio de una violencia infinita y que siempre pasa por el cuerpo. Estos sueños forman parte, entonces, de los lenguajes y los mundos virtuales, paralelos, espectrales de la historia colectiva (Giorgi 2004: 13).

Ante la falla del registro y el lenguaje encarnados en enfermedades mentales degenerativas y en el contexto del "Chile sin memoria" que, según César Zamorano (2016: 30), se presenta en Fruta podrida, los cuerpos anti-normativos de la novela se manifiestan para trazar una historia (en) común que conecta el pasado y el presente, el Norte y el Sur. Esa historia, y esos cuerpos potenciales, se encuentran marcados y toman forma a partir de la afectividad del duelo; un duelo inabarcable de aquellos cuerpos que ya no están, o que, como los bebés de María entregados a la ciencia, parecen 'no haber existido nunca', de modelos otros de solidaridad comunitaria y producción industrial en Ojo Seco, de una historia colectiva destinada al olvido en el contexto de un futuro imposible que proscribe la muerte.

Asimismo, la continuidad entre los cuerpos enfermos y las imágenes de la fruta en la novela tiene justamente su punto de origen en los intercambios que enlazan el transporte de la producción agrícola hacia el Norte con la instalación del hospital y la llegada de los equipos médicos de avanzada. Los imaginarios de contaminación y devenir movilizados en la novela se asientan, de este modo, en la historia concreta de los intercambios económicos de la región y la intervención del capital global. Refiriéndose a la crítica del capital de 
Karl Marx, la teórica Sara Ahmed utiliza la noción de 'economías afectivas' para ilustrar los modos en que las emociones "operan de forma similar al capital: el afecto no reside de manera positiva en el signo o el producto, sino que se origina como efecto de su circulación...las emociones circulan y se distribuyen no sólo a través del plano psíquico sino también del campo social" (Ahmed 2006: 120). Si el afecto se origina como efecto de su circulación, a medida que las historias locales (de la anciana, la fábrica, los sindicalistas, etc.) se experimentan, transmiten y comparten los cuerpos, moldeables, literalmente toman forma en Fruta podrida, orientándose hacia otros cuerpos y objetos y, en última instancia, hacia la comunidad de sujetos y signos que constituyen lo social. Mientras que la lógica del capital implica, según Marx, un ocultamiento de las huellas del proceso de producción detrás del bien de consumo, cuyo valor se desliga de la historia y el trabajo invertido en su elaboración, los cuerpos disidentes de la novela visibilizan, encarnan y reconstruyen la melancólica desaparición de esas huellas e historias.

\section{LA MOSCA AFRICANA: DEVENIR PLAGA}

Así, los imaginarios de putrefacción, contaminación e interpenetración entre cuerpos y especies son determinados por y habilitan la conformación de ensamblajes pasajeros, devenires inestables y comunidades efímeras. En este sentido y en términos de la articulación de lo comunitario a lo largo del texto, la enfermedad que aqueja a Zoila y a la anciana y la concomitante falla de la visión en ambos casos las posiciona en estrecha relación con el grupo de ciegos que se manifiesta en la plaza del pueblo de Ojo Seco (Meruane 2007: 110-111) y luego, hacia el final del texto, en la plaza donde se instala Zoila frente al Gran Hospital norteamericano (Meruane 2007: 180). A su vez, la enfermedad de Zoila es posiblemente, según los médicos, hereditaria (Meruane 2007: 25). Luego de preocuparse insistentemente ante la posibilidad de un contagio, María constata que la enfermedad de su hermana "no era contagiosa, al menos no del modo en que se pegaban las plagas que la Mayor destruía en el campo" (Meruane 2007: 25). Sin embargo, la enfermedad de la Menor parece habilitar otras vías de contagio o toxicidad -vías asentadas en la permeabilidad e interpenetración de los cuerpos. En primer lugar, Zoila es hija de una mujer local y un "importador extranjero" que no se hace cargo de ella-, en tanto producto del mestizaje cultural y, muy probablemente, racial, encarna un modo de toxicidad que, a partir de sus mismos genes, parece expandirse aceleradamente a su entorno. Zoila, con su boca que exhala una "empalagosa podredumbre" (Meruane 2007: 16), muerde a María en un ataque producido por su diabetes, y la herida se infecta, despidiendo un "olor nefasto" (Meruane 2007: 43) que reproduce y potencia el aliento de Zoila. Si bien la infección no afecta de forma perceptible al feto de María, perpetuamente embarazada, su propio estado sugiere la potencialidad de un traspaso, contaminación o contagio. Hacia el final de la novela, la enfermedad de Zoila se vuelve la enfermedad de María cuando ésta decide, en un gesto radical, envenenar las frutas, provocando un incidente internacional. Así, la toxicidad se 
expande fuera de las fronteras de Chile, afectando a aquellos cuerpos privilegiados para los cuales las hermanas producían frutas prístinas y perfectas.

Como argumenta Michel Foucault, la enfermedad y la peste se han constituido en mecanismos fundantes de control biopolítico, disciplinamiento y normalización subjetiva, confundiéndose a menudo con espacios y poblaciones específicas e identificadas como portadoras (Foucault 2006). En esta línea Barrientos propone que, en el caso de Fruta podrida, "la pestilencia y la enfermedad se entienden como una metáfora que muestra el envenenamiento de los cuerpos de seres que se encuentran en la periferia y que portan la toxicidad como forma natural en sus cuerpos" (Barrientos 2015: 97). ${ }^{9}$ Sin embargo, la enfermedad excede el ámbito de lo puramente simbólico en Fruta podrida. La enfermedad, más que como metáfora, opera aquí performativamente en tanto se torna una vía de exploración de la materialidad de los cuerpos. De esta forma, el despliegue del lenguaje literario en la novela se alinea con "los lenguajes literarios en torno al exterminio" en el sentido que apela a

representaciones que no invocan metafóricamente al cuerpo; la corporalidad no es allí solamente una construcción discursiva. Apuntan directamente al cuerpo, quieren suturar la distancia entre las palabras y las cosas, y cerrar el universo del lenguaje sobre sí mismo reconstruyendo o rehaciendo los cuerpos. $Y$ ese proceso no es meramente discursivo, sino que afecta - o aspira a afectar y a modificar - la materialidad misma de los cuerpos. Las ficciones literarias en torno al exterminio, entonces, trabajan en relación a esa fuerza performativa de los lenguajes y de las ficciones colectivas de la limpieza social, y su voluntad de hacer carne el verbo a partir de la eliminación de un cuerpo (Giorgi 2004: 10-11) ${ }^{10}$.

En Fruta podrida es justamente a partir del devenir (in)material de los cuerpos disidentes, y de su 'lenguaje celular', que se dirimen los modos en que los imaginarios locales viajan y se despliegan en otras latitudes. Trazando economías afectivas que, posicionadas más allá de lo humano y lo local, se definen a través de intercambios globales e inter-

\footnotetext{
9 Sin embargo, la pregunta por el origen, activada como discutí anteriormente en los imaginarios en torno a la medicalización de los cuerpos y la fruta en la novela, cobra nuevamente importancia en este caso: si la enfermedad de Zoila es probablemente hereditaria (Meruane 2007: 25), se instala una ambigüedad en torno a si ésta proviene de su madre o de su padre, el empresario del Norte. La postulación de una enfermedad cuyo origen es indeterminado e imposible de precisar inaugura la posibilidad de revertir, en un gesto desestabilizador, los imaginarios tóxicos y contaminantes de la periferia al instalar la imagen del padre como el portador de la enfermedad que viajaría desde el Norte hacia el Sur.

${ }^{10}$ En su análisis de los cuerpos anti-normativos que pueblan la narrativa argentina, Giorgi plantea que, al tiempo que "la imaginación y los lenguajes del exterminio como 'guerra interna' e 'higiene social' se juegan alrededor de la 'vida' colectiva, entre lo biológico y lo social, entre lo 'natural' y lo 'cultural', entre lo animal y lo humano" y emergen, por tanto, "en relación al universo biopolítico de la construcción de lo colectivo a partir del modelado de la 'vida' de los cuerpos y las poblaciones", dichos imaginarios y lenguajes "iluminan... una zona entre el lenguaje y la vida, entre la cultura y el cuerpo" (Giorgi 2004: 10).
} 
especie, los imaginarios de contagio y toxicidad operan allí para producir cuerpos otros que habitan posiciones siempre liminales, oscilando entre el pasado y el presente, lo humano y lo animal, lo local y lo global.

Así, es una plaga de moscas la que produce, en primera instancia y con anterioridad al incidente de envenenamiento final por parte de María, la contaminación de la fruta; la mosca de la fruta, o mosca africana, más pequeña y más fértil que la doméstica, que viaja: "malditas moscas cosmopolitas!, en nuestra mercancía de exportación y en el postre de los turistas" (Meruane 2007: 76). Si el cuerpo en putrefacción de Zoila se vuelve indistinguible de las moscas que lo acechan, es posible pensar que es ese mismo cuerpo y su toxicidad el que, en un devenir potencial, simbólicamente contamina la 'fruta podrida' de la novela. Así como la fruta expande su toxicidad al ámbito global, el viaje que una Zoila cada vez más enferma emprende, cual mosca africana cosmopolita, hacia Estados Unidos al final de la novela espeja ese mismo trayecto contaminante que, bajo el signo del inmigrante, se traslada desde la periferia hacia el centro.

Mel Chen entiende la toxicidad como "un agente activo y animado", y señala que "los intereses en torno a la toxicidad se encuentran particularmente (si bien muchas veces de modo encubierto) marcados en términos de raza y sexualidad". De hecho, sugiere Chen, "las toxinas participan vívidamente en la constitución y materialización racial de espacios, cuerpos humanos y no humanos, entidades vivas e inertes, y eventos como las amenazas a la salud pública" (Chen 2012: 10). En el caso de Fruta podrida, la toxicidad constituye una "zona de extensión de la raza" y, me interesa añadir aquí, del género, o un punto de intersección de la raza, el género y el medio ambiente. El cuerpo femenino, mestizo y de clase trabajadora se representa como un cuerpo contaminado genéticamente (en el caso de Zoila, a través de una enfermedad hereditaria), un cuerpo susceptible de infectar o contaminar a otros (en el caso de María, mediante la intoxicación de la fruta). Un cuerpo capaz de albergar deseos anti-normativos que, desafiando la lógica médica en el caso de Zoila y la lógica moral en el caso de María, tienden o a la reproducción indiscriminada de una clase social supuestamente indeseada a través de los embarazos constantes de María, emulando bajo una mirada clasista el comportamiento de una plaga, o, en el otro extremo, a la aniquilación total de la vida propia y ajena mediante la resistencia de Zoila al tratamiento, sus ataques terroristas al hospital norteamericanos y el envenenamiento de la fruta por parte de María. En este sentido, ambas trayectorias se pliegan una sobre otra bajo el signo de un exterminio radical que emula y reproduce en los cuerpos de las dos hermanas la respuesta ante una plaga agrícola - es decir, un efecto pesticida. Si durante el desarrollo del texto Zoila y María, tan opuestas en un comienzo, se asemejan cada vez más una a la otra al punto que hacia el final la toxicidad destructiva de Zoila parece traspasarse a María, ambas comparten el destino de los insectos que plagan el texto: la aniquilación o el exterminio bajo la presión de los circuitos de producción económica y biopolítica global.

En este sentido, en términos raciales la toxicidad adquiere en el caso de la novela un origen claro, la mosca africana; origen que espeja, replica y reafirma la otredad racial latinoamericana al tiempo que visibiliza la complejidad de los modos en que la racialidad 
circula y se articula de manera transnacional a través de intercambios y circuitos económicos globales. En un pasaje que revela una percibida superioridad geopolítica y racial por parte de María, la protagonista desnuda ante los ojos de su hermana su cuerpo femenino y latino al tiempo que orina, articulando un discurso atravesado por lo excrementicio, por los desperdicios de un cuerpo irreversible y paradójicamente marcado en términos de género, raza y clase social:

Maldita mosca africana, susurra [María] abriéndose el uniforme, desnudando sus pesados pezones hinchados y oscuros mientras mis ojos observan que uno es puntiagudo y el otro, más grueso y cubierto de granos; maldita mosca del África, repite sentándose en la taza y meando un largo chorro. ¿Serán africanas todas las pestes del mundo? ¿serán africanos también los aguaceros que hacen caer la fruta en primavera o la cubren de hongo en verano?, suspira, haciendo percutir sus uńas recortadas en la loza del váter. Y se limpia de adelante hacia atrás antes de subirse los calzones y subirse el cierre. Habría que acabar con África, dice, categórica, a nadie le hace falta ese inmundo continente (Meruane 2007: 84-85).

Replicando la abyección de la escena discutida anteriormente en la que María ingiere la orina de su hermana, la corporalidad en este pasaje y la vulnerabilidad de su cuerpo desnudo de mujer embarazada y explotada tanto laboral como sexualmente, junto con el carácter excrementicio de la narración, reafirma la violencia que María ejerce contra lo africano a través de su discurso. Una violencia discursiva que se proyecta narrativamente sobre un cuerpo irreversiblemente marcado en términos de género, un cuerpo que se reproduce constantemente, cual la plaga de la mosca africana que incita su enojo. Evitando el riesgo de romantizar estos cuerpos marginales en perpetuo devenir que presenta la novela, este pasaje posiciona a estos sujetos como participantes activos en imaginarios, prácticas y circuitos globales de violencia y toxicidad. Violencias constitutivas de corporalidades mestizas, trabajadoras, femeninas, explotadas y violentadas que, plegándose sobre sí mismas, presentan complejas dinámicas geopolíticas centro-periferia y Sur-Sur (un Sur global que, hacia el final de la novela se revela, bajo el signo de la exportación agrícola y la inmigración, como irremediable y amenazantemente tóxico). Así, estos modos de violencia y abyección señalan conexiones invisibles entre escenas y cuerpos aparentemente distanciados, pero íntimamente vinculados por los circuitos de violencia de género, laboral, racial, sexista, clasista, geopolítica y especista y por el tránsito de las múltiples materialidades -representadas aquí por la ominosa mosca africana- que la economía del capitalismo global posibilita.

Estos circuitos de violencia se imbrican en la novela y permiten un abordaje complejo a las representaciones del cuerpo femenino en la actualidad. Cuerpos que evidencian modos de resistencia a marcos normativos, pero a la vez, sugiero aquí, plantean y visibilizan una (bio) política expandida, es decir, la necesidad de interrogar escalas que exceden lo propiamente humano para pensar la subjetividad femenina. Explotando conexiones latentes con otros 
cuerpos y seres, los sujetos femeninos de Fruta podrida participan de una serie de 'devenires' que habilitan formas otras de pensar la problemática de género: más que como entidades auto-contenidas e independientes del medio, sus corporalidades emergen y toman forma a partir de una radical apertura hacia cuerpos y objetos no humanos. Es justamente a través de su apertura radical que estos cuerpos, lejos de des-politizarse, literalmente encarnan memorias locales en un contexto global homogeneizador de la diferencia que invisibiliza y desarticula el tejido social del campo chileno. En continuidad con la trayectoria de Zoila, cuya (des)composición física se asienta en modos de registro escritural, la materialidad enrarecida de estos cuerpos humanos, animales y vegetales y su subsecuente desaparición o exterminio emerge aquí como testimonio, rastro y resto de una historia común. En última instancia, esa búsqueda se asocia en Fruta podrida a una interrogación sostenida en torno a la forma y la noción misma de la corporalidad femenina -corporalidades marcadas en términos de raza, sexualidad, clase social y posicionamiento geopolítico- en el contexto del post-humanismo contemporáneo. Una interrogación que en la novela se nutre de los imaginarios y prácticas de toxicidad que producen y, a la vez, son producidos por estos cuerpos, visibilizando así los ensamblajes corporales y materiales y las trayectorias potenciales que el campo chileno habilita en su circulación simbólica y económica global.

\section{Obras CITADas}

Ahmed, Sara. 2006. Queer Phenomenology: Orientations, Objects, Others. Durham: Duke University Press. . 2004. "Affective economies". Social Text 79 (22): 117-139.

Barrientos, Mónica. 2015. "La fisura del espacio y la toxicidad de los cuerpos: Guadalupe Santa Cruz's El contagio and Lina Meruane's Fruta podrida". Chasqui: Revista de literatura latinoamericana 44 (1): 91-103.

Bennett, Jane. 2010. Vibrant Matter: A Political Ecology of Things. Durham: Duke University Press.

Chen, Mel. 2012. Animacies: Biopolitics, Racial Mattering, and Queer Affect. Durham: Duke University Press.

Deleuze, Gilles \& Félix Guattari. 1987. A Thousand Plateaus: Capitalism and Schizophrenia. Minneapolis: University of Minnesota Press.

Foucault, Michel. 1998. Historia de la sexualidad. México: Siglo Veintiuno. . 2006. Seguridad, territorio, población: Curso en el Collège de France (1977-1978). México: Fondo de Cultura Económica.

Giorgi, Gabriel. 2004. Sueños de exterminio: Homosexualidad y representación en la literatura argentina contemporánea. Rosario: Beatriz Viterbo. . 2014. Formas comunes: Animalidad, cultura, biopolitica. Buenos Aires: Eterna Cadencia.

Gregg, Melissa \& Gregory Seigworth (Eds.). 2010. The Affect Theory Reader. Durham: 
Duke University Press.

Grosz, Elizabeth. 2011. Becoming Undone: Darwinian Reflections on Art, Politics and Life. Durham: Duke University Press.

Keizman, Betina. 2017. "Las dinámicas de lo viviente: Repetición, supervivencia y vidas potenciales". 452 F: Revista de Teoría de la Literatura y Literatura Comparada 17: $102-121$.

Meruane, Lina. 2015. Fruta podrida. Buenos Aires: Eterna Cadencia.

Quintana, Isabel. 2017. "Parcelas de vida: El arte y sus restos". 452 F: Revista de Teoría de la Literatura y Literatura Comparada 17: 122-138.

Zamorano, César. 2016. "Capitalismo y producción de subjetividad en Mano de obra y Fruta podrida”. Revista Iberoamericana 82 (254): 27-43. 
